Arq. Bras. Med. Vet. Zootec., v.56, n.2, p.277-279, 2004

\title{
Comunicação
}

[Communication]

\section{Isolamento de Pasteurella spp. e Vibrio spp. em robalos (Dicentrarchus labrax). Susceptibilidade a diferentes grupos de antibióticos}

\author{
[Isolation of Pasteurella spp. and Vibrio spp. in European sea bass (Dicentrarchus labrax). Susceptibility to different \\ antibiotic groups]
}

\author{
M.J. Saavedra, R.D. Brito, M. Sousa, A. Alves, P. Rema \\ Universidade de Trás-os-Montes e Alto Douro - CECAV \\ Apt.1013, 5000-911 \\ Vila Real, Portugal
}

O robalo (Dicentrarchus labrax) é uma espécie de interesse comercial reconhecido, ocupando posição de destaque no consumo de peixe nos países europeus (Blanquet, 1998).

Diversos estudos demonstram que grande parte dos surtos bacterianos ocorridos em explorações de D. labrax, sem sinais exteriores da doença, são devidos às deficiências de manejo, factores de estresse ambiental e qualidade da água de cultivo.

As doenças infecciosas mais freqüentes nos cultivos de peixes são as de origem bacteriana, com predominância de Vibrio spp., Pasteurella piscicida e Myxobacter spp. A pasteurelose, cujo agente é a $P$. piscicida em peixes de água salgada, é a doença infecciosa bacteriana de maior freqüência (Schmidt et al., 2000). A presença desses microrganismos determina quebras significativas na produção e na rentabilidade da exploração de peixes. Para prevenir a morbilidade e mortalidade na exploração recorre-se ao uso de antibióticos. Todavia, a utilização sistemática de antibióticos como prática veterinária de tratamento conduz ao aparecimento de estirpes resistentes.

Os objetivos deste trabalho foram determinar a resistência de agentes bacterianos isolados aos antibióticos beta-lactâmicos e aminoglicosídeos, às tetraciclinas e ao cloranfenicol (Adams et al., 1998; Schmidt et al., 2000; Teo et al., 2000) e estimar a correlação entre as alterações histopatológicas e os isolados bacterianos.

O experimento foi realizado na unidade experimental de piscicultura da Universidade de Trás-os-Montes e Alto Douro durante um ensaio de crescimento feito com juvenis de robalo, onde foi observada mortalidade anormal. Após os primeiros indícios de doença, o ensaio foi interrompido e procedeu-se à recolha aleatória de 10 peixes para posterior análise.

A necropsia dos cadáveres e isolamento de estirpes bacterianas foi feita a partir de amostras de água e de peixes (pele e rins). Foram utilizados meios selectivos e diferenciais (TCBS, GSP, ágar-MacConkey, ágar-sangue) de acordo com as espécies bacterianas. Durante a necropsia procedeu-se à execução de esfregaços frescos de pele e de brânquias para detecção de formas parasitárias. Após a incubação a $22^{\circ} \mathrm{C}$, verificouse o desenvolvimento de diferentes colónias sendo a identificação das estirpes efectuada pelo sistema API20NE (bioMérieux), seguindo a metodologia indicada pelo fabricante.

O estudo da susceptibilidade aos agentes antibacterianos foi efectuado pela técnica de difusão em ágar, seguindo as normas do National Committee for Clinical Labortory Standards (National..., 1997), com 19 antibióticos: carbenicilina, piperacilina, piperacilina + tazobactan, amoxicilina, amoxicilina + ác.

Recebido para publicação em 23 de abril de 2003

E-mail: saavedra@utad.pt 


\section{Saavedra et al.}

clavulânico, ticarcilina, ticarcilina + ác. clavulânico, ampicilina, cefalotina, cefoperazona, cefepime, cefotaxime, aztreonamo, imipenemo, tetraciclina, norfloxacina, estreptomicina, tobramicina, canamicina e cloranfenicol.

As amostras de tecidos recolhidas foram fixadas em formol tamponado a $10 \%$, incluídas em parafina e posteriormente cortadas com $3 \mu \mathrm{m}$ de espessura e corados pela hematoxilina-eosina.

Nas brânquias foram encontradas inúmeras formas parasitárias de Dactylogyrus spp. Não foram observadas quaisquer alterações macroscópicas externas ou nos órgãos internos. O exame microscópico revelou inflamação aguda moderada das brânquias e esteatose hepatocitária exuberante em alguns dos animais.

A identificação dos agentes bacterianos presentes na água e na pele permitiu classificar as estirpes como Pasteurella haemolytica (50\%), Pasteurella multocida (25\%) e Vibrio spp.(25\%). Nas amostras de rins não foram isoladas estirpes bacterianas. Cerca de $66,7 \%$ das Pasteurella spp. apresentaram resistência à amoxicilina e ticarcilina (Fig. 1).

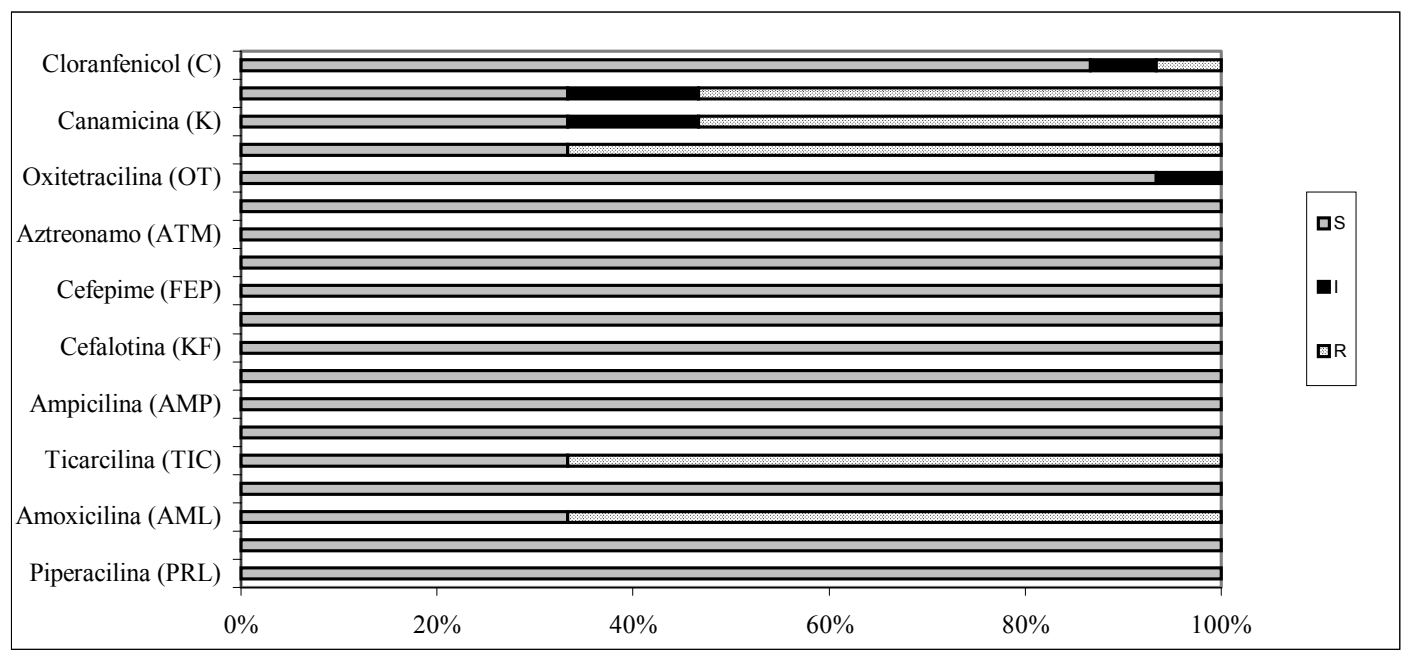

Figura 1. Perfil de susceptibilidade aos antimicrobianos testados para Pasteurella spp.

Em relação aos aminoglicosídeos, as Pasteurella spp. apresentaram resistência à estreptomicina $(66,7 \%)$. Observou-se elevada susceptibilidade à oxitetraciclina e ao cloranfenicol, respectivamente, $93 \%$ e $87 \%$. Nas estirpes de Vibrio spp. observou-se resistência de $80 \%$ à carbenicilina e de $40 \%$ à amoxicilina e ampicilina (Fig. 2). Todos os isolados apresentaram susceptibilidade ao aztreonamo. Especialmente relevante foi a elevada resistência das estirpes de Vibrio à estreptomicina (100\%). Todos os isolados apresentaram susceptibilidade à tetraciclina e ao cloranfenicol.
Os resultados sugerem que o estado de morbilidade dos robalos (D. labrax) pode ser atribuído à elevada carga parasitária, com agravamento pela presença de bactérias, factores que estiveram na origem do elevado índice de mortalidade. Foram realizados testes bioquímicos para complementar a biotipificação numérica realizada pelos testes comerciais API 20NE. Concluiu-se que o cloranfenicol e a tetraciclina foram os antimicrobianos mais eficazes para o tratamento da infecção por esses agentes. Ressalta-se que o uso do cloranfenicol não é recomendado para ser usado em animais destinados ao consumo humano. 


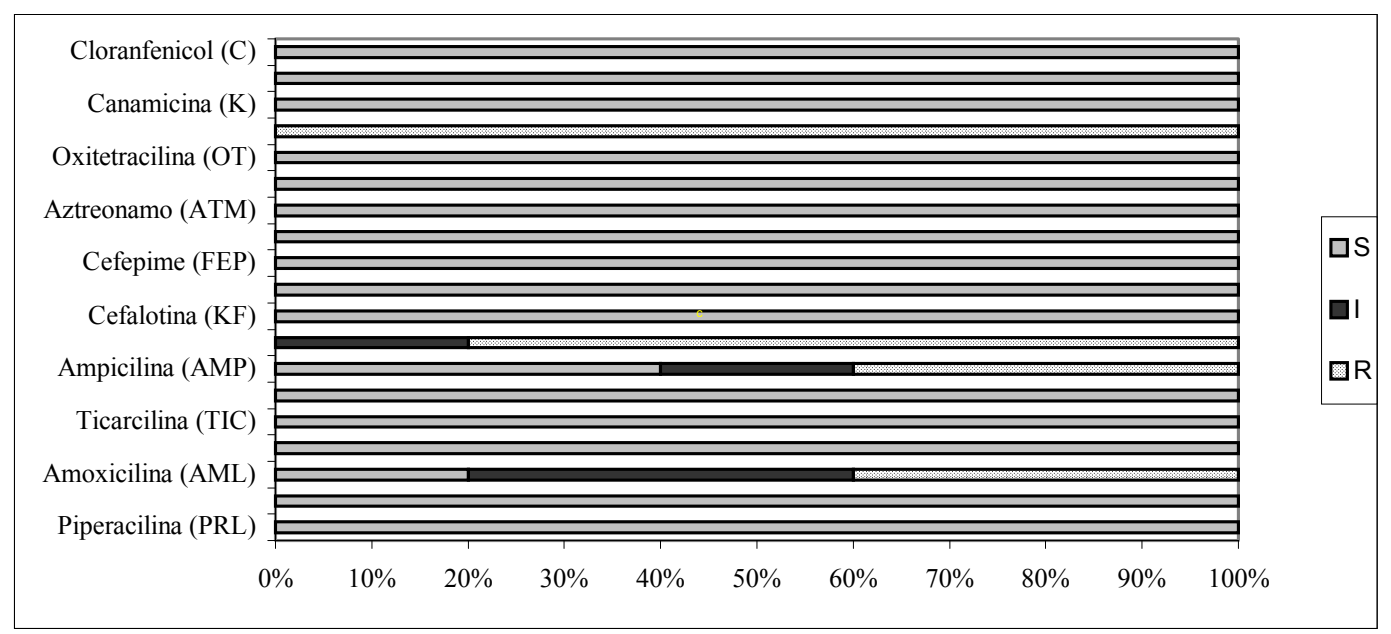

Figura 2. Perfil de susceptibilidade aos grupos de antibióticos testados para Vibrio spp.

Palavras-chave: Dicentrarchus labrax, antibióticos, resistência, pasteurelose

\begin{abstract}
The most frequent infectious diseases that affect fish are those of bacterial origin. In European sea bass fish farms (Dicentrarchus labrax) are included Vibrio spp., Pasteurella piscicida and Myxobacter spp. In addition to these, it is also possible to find, although lesser frequently, other pathogenic agents such as Pseudomonas spp., Aeromonas spp., Staphylococcus epidermis, Streptococcus spp. and Enterobacter spp. The presence of these micro-organisms in fish farms contributes for a significant decrease in fish production and subsequent loss of profitability in these aquaculture units. The use of antibiotics may therefore be necessary as a prophylactic measure although their systematic utilization leads to the development of strains of antibiotic resistant bacteria. Bearing that in mind, a survey was conducted on the susceptibility of isolated strains of bacteria found in juvenile European sea bass. It was concluded that chloranphenicol and tetracycline are two important antibiotic alternatives for therapy against isolated bacterial agents.
\end{abstract}

Keywords: Dicentrarchus labrax, antibiotics, resistant, bacteria, pasteurellosis

\section{REFERÊNCIAS BIBLIOGRÁFICAS}

ADAMS, C.A.; AUSTIN, B.; MEADEN, P.G. et al. Molecular characterization of plasmid mediated oxytetracycline resistance in Aeromonas salmonicida. Appl. Environ. Microbiol., v.64, p.4194-4201, 1998.

BLANQUET, I. Robalo. In: MARIA ARMANDA, H. (Ed.) Manual de aquaculture, 1998. p.177-187.

NATIONAL Committe for Clinical Laboratory Standards. Performance standards for antimicrobial disk susceptibility tests. Approved standards. M2-A5. Villanova, Pa., 5.ed., 1997.
ROBERTS, R.J. The bacteriology of teleosts. In: ROBERTS R.J. (Ed.) Fish pathology. 2.ed. Baillière Tindall, 1989. p.289-319.

SCHMIDT, A.S.; BRUUN, M.S.; DALSGAARD, I. et al. Occurrence of antimicromial resistance in fish-pathogenic and envinonmental bacteria associated with four danish rainbow trout farms. Appl. Environ. Microbiol., v.66, p.49084915,2000 .

TEO, J.W.B.P.; SUWANTO, A.; POH, C.L. Novel betalactamase genes from two environmental isolates of Vibrio harveyi. Antimicrob. Agents Chemother., v.44, p.1309-1314, 2000. 